\title{
Economic tools to promote transparency and comparability in the Paris Agreement
}

\section{Citation}

Aldy, Joseph, William Pizer, Massimo Tavoni, Lara Aleluia Reis, Keigo Akimoto, Geoffrey Blanford, Carlo Carraro, et al. 2016. "Economic Tools to Promote Transparency and Comparability in the Paris Agreement." Nature Climate Change 6 (11) (August 22): 1000-1004. doi:10.1038/nclimate3106.

\section{Published Version}

doi:10.1038/nclimate3106

\section{Permanent link}

http://nrs.harvard.edu/urn-3:HUL.InstRepos:29914190

\section{Terms of Use}

This article was downloaded from Harvard University's DASH repository, and is made available under the terms and conditions applicable to Open Access Policy Articles, as set forth at http:// nrs.harvard.edu/urn-3:HUL.InstRepos:dash.current.terms-of-use\#OAP

\section{Share Your Story}

The Harvard community has made this article openly available.

Please share how this access benefits you. Submit a story.

\section{Accessibility}


Economic Tools to Promote Transparency and Comparability in the Paris Agreement

Joseph Aldy ${ }^{1,2,3,4 *}$, William Pizer, ${ }^{2,3,5}$, Massimo Tavoni ${ }^{6,7,8}$, Lara Aleluia Reis ${ }^{6}$, Keigo Akimoto ${ }^{9}$, Geoffrey Blanford $^{10}$, Carlo Carraro ${ }^{6,7,11}$, Leon E. Clarke ${ }^{12}$, James Edmonds ${ }^{12}$, Gokul C. Iyer ${ }^{12}$, Haewon C. McJeon ${ }^{12}$, Richard Richels ${ }^{10}$, Steven Rose ${ }^{10}$, Fuminori Sano ${ }^{9}$

Final Pre-Publication Version

The Paris Agreement culminates a six-year transition toward an international climate policy architecture based on parties submitting national pledges every five years. ${ }^{1}$ An important policy task will be to assess and compare these contributions. ${ }^{2,3}$ We use four integrated assessment models to produce metrics of Paris Agreement pledges, and show differentiated effort across countries: wealthier countries pledge to undertake greater emission reductions with higher costs. The pledges fall in the lower end of the distributions of the social cost of carbon (SCC) and the cost-minimizing path to limiting warming to $2^{\circ} \mathrm{C}$, suggesting insufficient global ambition in light of leaders' climate goals. Countries' marginal abatement costs vary by two orders of magnitude, illustrating that large efficiency gains are available through joint mitigation efforts and/or carbon price coordination. Marginal costs rise almost proportionally with income, but full policy costs reveal more complex regional patterns due to terms of trade effects.

\footnotetext{
${ }^{1}$ Harvard University, Cambridge, Massachusetts 02138, USA

${ }^{2}$ Resources for the Future, Washington, DC 20036, USA

${ }^{3}$ National Bureau of Economic Research, Cambridge, Massachusetts 02138, USA

${ }^{4}$ Center for Strategic and International Studies, Washington, DC 20036, USA

${ }^{5}$ Duke University, Durham, NC 27708, USA

${ }^{6}$ Fondazione Eni Enrico Mattei (FEEM), Milan 20123, Italy

${ }^{7}$ Centro Euromediterraneo sui Cambiamenti Climatici (CMCC), Milan 20123, Italy

${ }^{8}$ Politecnico di Milano, Department of Management and Economics, Milan 20133, Italy

${ }^{9}$ Research Institute of Innovative Technology for the Earth, Kyoto 619-0292, Japan

${ }^{10}$ Energy and Environmental Analysis Research Group, Electric Power Research Institute, Palo Alto, California 94304, USA

${ }^{11}$ University of Venice, Venice 30123, Italy

12 Joint Global Change Research Institute, Pacific Northwest National Laboratory, College Park, Maryland 20740, USA
} 
Accepted Nature Climate Change 2016, doi:10.1038/nclimate3106, available online at http://www.nature.com/nclimate/journal/vaop/ncurrent/full/nclimate3106.html.

The pledge and review approach formalized in the Paris Agreement requires a well-functioning transparency regime. Given the discretion left with national governments on the form of their mitigation pledges, or Intended Nationally Determined Contributions (INDCs), assessments are necessary to estimate and compare their impacts. Such comparisons will be of interest to environmental stakeholders who want to pressure those countries with relatively modest mitigation contributions. Business stakeholders may focus on assessments of INDCs' economic impacts, specifically energy price and cost impacts among trade partners.

Beyond stakeholder interest, transparency and comparability can promote the stability and facilitate greater ambition of an international climate agreement. Transparent reviews serve to enhance the credibility and likelihood that a party will deliver on its announced pledge, especially with repeating rounds of pledge and review ${ }^{4,5,6}$. Assessments of pledges reveal countries' preferences and interests ${ }^{1}$, enabling more-informed negotiations. International institutions to facilitate transparency - through the collection, analysis, and dissemination of information on countries' pledges - can lower the costs of international agreements and enhance their legitimacy ${ }^{7}$. Voluntary pledge and review can result in broad participation $^{8,9}$, as evident in the Paris Agreement. In various contexts, including international trade and common pool resource management, the demonstration of reciprocal actions has resulted in fewer deviations from agreements and positive reactions by members of the agreement ${ }^{10}$.

The long-term success of the Paris Agreement likely depends on assessments of whether comparable countries undertake comparable mitigation efforts. Such assessments are complicated by the variation in the form of pledges: targets specified in terms of a base year, a forecast, or emissions intensity; peaking year; renewable energy goals; etc. Evaluating the comparability of mitigation effort highlights INDCs' economic efficiency and equity implications, which may be critical to subsequent negotiations and related domestic mitigation actions. These assessments can characterize overall mitigation ambition, and add value to related analyses, such as UNEP emissions gap reports and 
Accepted Nature Climate Change 2016, doi:10.1038/nclimate3106, available online at http://www.nature.com/nclimate/journal/vaop/ncurrent/full/nclimate3106.html.

academic papers ${ }^{11,12}$, that will inform the Paris Agreement's global stocktakings. Let us enumerate how economic analysis can inform INDC assessments.

First, some INDCs, by design, require economic forecasts. Pledges based on reductions from a forecast emissions or emission intensity reflect model-based forecasts of emissions and/or GDP. Assessing their robustness to alternative assumptions and translating the pledge into emission levels requires modeling. Second, stakeholders and governments will want apples-to-apples, comprehensive comparisons among INDCs. This requires frameworks employing internally consistent data and modeling assumptions to produce comparability metrics. The national communications processes show that countries often produce measures of mitigation effort that are not comparable ${ }^{13}$. Third, only integrated, multi-country assessments can account for cross-border impacts of INDCs occurring via international trade. Fourth, economic analyses of INDCs can focus attention on policy learning ${ }^{14-16}$, by illustrating opportunities for more cost-effective domestic policies and highlighting the benefits of bilateral linking of domestic programs ${ }^{17}$. Finally, assessments at this stage can identify the data and modeling needs for ex post review of INDCs.

To identify metrics for our analysis, we first define mitigation effort as the emissions, energy, and economic outcomes that occur as a result of explicit implementation of domestic mitigation programs. We consider metrics - physical and economic outcomes such as emissions, prices, and aggregate economic activity - that are comprehensive, measurable and replicable, and universal ${ }^{2,3}$. No single metric satisfies all three principles. Some metrics - emissions relative to a base year, changes in emission intensity, and energy and carbon market prices - are observable but not comprehensive. Deviations from forecast emission levels and/or the economic costs of such deviations are the most comprehensive measures, but neither universal nor easily measurable. Recognizing these tradeoffs, we present a suite of emissions, prices, and cost metrics to provide a rich characterization of countries' 
pledged efforts. We emphasize deviations from forecast emission levels and economic cost as the most comprehensive measures of mitigation effort.

Previous research evaluated the Copenhagen Accord pledges in terms of reductions from 2020 emission forecasts to assess aggregate impacts ${ }^{18}$, and a broader set of economic metrics, with an emphasis on the impacts of emission trading ${ }^{19}$. McKibbin et $\mathrm{al}^{20}$ compare the "stringency" of pledges by large economies using a subset of our metrics (carbon price, cost as a share of GDP). These studies are limited to one model. Multi-model comparison projects (e.g. EMF22 ${ }^{21}$, LIMITS $^{22}$, and AMPERE ${ }^{23}$ ) have primarily focused on long-term targets, although some research has considered national goals and used similar metrics ${ }^{24}$.

Assessments of future mitigation effort are inherently uncertain ${ }^{25}$. Employing multiple metrics and multiple tools can serve to highlight the robust findings about INDCs and identify those impacts, policies, and goals that merit additional investigation. Policymakers and stakeholders may benefit by learning about how the INDCs compare with the SCC - in the context of maximizing net social benefits and the cost-minimizing pathway to limiting warming to $2^{\circ} \mathrm{C}$ - in the context of cost-effective attainment of Paris's long-term objective. Given uncertainties in the benefits of mitigating climate change and the trajectories of attaining temperature objectives, we use the SCC distribution produced by the US government and extract from the IPCC AR5 scenario database the distribution of all model runs that limit warming to no more than $2^{\circ} \mathrm{C}$ with a $50 \%$ probability (see Methods for details and caveats). Alternative approaches to incorporating uncertainty in modeling climate damages - such as in dynamic stochastic general equilibrium models ${ }^{26}$ - may better represent how uncertainty influences the SCC. We retain the USG SCC since it serves as a focal point for government decisionmaking.

To simulate, assess, and compare pledges, we have employed four integrated assessment models (DNE21+, GCAM, MERGE and WITCH; see Methods for details). These models differ in terms of regional, technological, sectoral and economic representation. We have simulated the contributions 
Accepted Nature Climate Change 2016, doi:10.1038/nclimate3106, available online at http://www.nature.com/nclimate/journal/vaop/ncurrent/full/nclimate3106.html.

submitted as of mid-February 2016: we have assumed cost-minimizing attainment of the INDCs' emission goals. While the form of contribution varied among the countries we evaluated, the models produced a consistent set of emission, price, and cost metrics. We quantify the economic costs of mitigation scaled by GDP and the carbon tax for that country to achieve cost-effectively its pledge (Marginal Abatement Cost, MAC). As evident below, the two metrics are only partially related. We report metrics averaged between 2025 and 2030, given the variation in INDC target years. Table 1 summarizes the modeling results.

Figure 1 shows the estimated emission reductions from business-as-usual in the major economies alongside marginal abatement cost and cost as a share of GDP. The results illustrate differentiated effort, with wealthier countries generally mitigating more emissions. Emission reductions correlate well with marginal costs but not with total economic costs, in line with the empirical literature $^{27}$. The DNE21+ model estimates higher total economic costs for South Africa (2.1\%), which primarily reflects that model's cross-border spillovers - including falling demand for South African coal anticipated by near-global implementation of INDCs. Japan, a country with low emissions and fewer mitigation options compared to other industrialized countries, shows comparable costs as a percentage of GDP to the U.S. and EU, but fewer emission reductions and significantly higher marginal costs (in GCAM and DNE21+).

In Figure 2, we compare marginal costs across countries. The figure highlights the potential gains to international emissions trading and how mitigation efforts compare to global benefit estimates and $2^{\circ} \mathrm{C}$ pathways. The considerable variation in marginal costs suggests large gains to international cooperation: when simulating cost-minimizing global attainment of the Paris INDCS, the DNE21+, MERGE, and WITCH models estimate a global carbon price of 7-28 US\$2015/tCO ${ }_{2} \mathrm{e}$. Important institutional developments to promote joint mitigation measures among countries, including international emissions trading or carbon tax coordination, could deliver significant economic gains ${ }^{28,29}$. 
Accepted Nature Climate Change 2016, doi:10.1038/nclimate3106, available online at http://www.nature.com/nclimate/journal/vaop/ncurrent/full/nclimate3106.html.

We also compare the INDCs' marginal abatement costs to the SCC and the cost-minimizing path to limiting warming to $2^{\circ} \mathrm{C}$. The global carbon prices appear to be well below the mean SCC (SCC $=57$ US\$2015/ $/ \mathrm{tCO}_{2}$ in 2030), but consistent with the lower end of the SCC distribution. Likewise, the marginal abatement costs fall below the mean cost associated with a cost-minimizing path to limiting warming to $2^{\circ} \mathrm{C}$. These comparisons may indicate insufficient ambition in the Paris Agreement in terms of global welfare and the long-term temperature objective. However, some countries bear marginal costs exceeding the mean marginal benefits or the mean cost-minimizing level of a $2^{\circ} \mathrm{C}$ objective, such as Japan and the EU as modelled by DNE21+.

To illustrate how mitigation effort varies with wealth, Figure 3 plots the estimated policy costs (both marginal costs and total cost expressed as a share of GDP) against per capita income. The figure reveals two regional clusters - one among emerging and developing economies and the other of highincome countries. As a measure of the distributional impacts of INDCs, we compute a 'burden elasticity of income': the variation in policy costs (either marginal or total) for a percentage point increase in per capita income. For marginal abatement costs, we estimate a burden elasticity of 1.1 (SE=0.25, statistically significant at $0.1 \%$ level), suggesting relatively progressive distributional impacts of INDCs. When measured using total costs, however, the burden elasticity of income is below unity (0.42) and not statistically significant $(\mathrm{SE}=0.25)$. Higher marginal costs do not necessarily imply higher total policy costs; trade-exposed and carbon-intensive countries (e.g., many developing economies) tend to experience higher GDP losses for a given carbon price, as already shown by Stern et. al. (2012). The models' estimates only represent mitigation costs; they do not account for climate benefits or local air quality co-benefits. Nonetheless, there is significant variation across countries and models. Model assumptions matter.

Table 1 includes additional metrics that are less comprehensive than the cost and emission reduction from BAU measures and show how some metrics naturally favor certain countries. Measuring 
Accepted Nature Climate Change 2016, doi:10.1038/nclimate3106, available online at http://www.nature.com/nclimate/journal/vaop/ncurrent/full/nclimate3106.html.

emissions versus a 1990 base year is unfavorable to emerging countries and those with faster population and/or economic growth (e.g., the United States). With a 2005 base year, the U.S. and EU appear comparable and, for reductions from 2025-2030 forecast levels, countries are more comparable (but with the income gradation noted above). The carbon and energy price metrics suggest comparable price increases for the U.S., EU, and Japan. While the MERGE model estimates lower carbon prices for these countries than the other models, each model shows fairly comparable carbon prices among this high-income group. China, India, South Africa, and Russia have much smaller, comparable price impacts. Emission intensity tends to favor faster growing economies; China's INDC shows a reduction in emission intensity similar to that of the United States.

The Paris Agreement is widely viewed as a success because of the design of an institutional framework it establishes, not its near-term mitigation outcomes. Its continued success requires countries to deliver greater emission mitigation in subsequent rounds of pledging, which will depend on rigorous, transparent reviews of mitigation pledges and outcomes. As the parties to the agreement work to implement the new transparency mechanism, economic analysis will be critical. Translating the various types of pledges in order to estimate aggregate effects and make apples-to-apples comparisons requires economic tools. The more comprehensive measures of mitigation effort require economic modeling, as do the consequences of global INDC implementation. Our work illustrates a framework for organizing future modeling of pledges to inform the transparency regime. Finally, economic modeling of INDCs can promote policy learning and cost-effective mitigation, which can enable the ratcheting up of ambition over time. 
Accepted Nature Climate Change 2016, doi:10.1038/nclimate3106, available online at http://www.nature.com/nclimate/journal/vaop/ncurrent/full/nclimate3106.html.

References

1. Keohane, Robert O. \& Victor, David G. Cooperation and discord in global climate policy. Nature Climate Change 6, 570-575 (2016).

2. Aldy, J. E. \& Pizer, W. A. Alternative Metrics for Comparing Domestic Climate Change Mitigation Efforts and the Emerging International Climate Policy Architecture. Review of Environmental Economics and Policy 10, 3-24 (2016).

3. Aldy, J. E., Pizer, W. A. \& Akimoto, K. Comparing emissions mitigation efforts across countries. Climate Policy 1-15 (2016). doi:10.1080/14693062.2015.1119098

4. Schelling, T. C. An essay on bargaining. The American Economic Review 281-306 (1956).

5. Chayes, A. \& Chayes, A. H. Compliance without enforcement: state behavior under regulatory treaties. Negotiation Journal 7, 311-330 (1991).

6. Barrett, S. Environment and Statecraft: the Strategy of Environmental Treaty-Making. Management of Environmental Quality: An International Journal 14, 622-623 (2003).

7. Bodansky, D., Brunnée, J. \& Hey, E. The Oxford handbook of international environmental law. (Oxford University Press, 2007).

8. Victor, D. G. Fragmented carbon markets and reluctant nations: implications for the design of effective architectures. Architectures for agreement: Addressing global climate change in the postKyoto world 133-172 (2007).

9. Pizer, W. A. Practical global climate policy. Architectures for Agreement: Addressing Global Climate Change in the Post-Kyoto World 280-314 (2007).

10. Ostrom, E. A behavioral approach to the rational choice theory of collective action: Presidential address, American Political Science Association, 1997. American political science review 92, 1-22 (1998). 
11. den Elzen, M. G. J., Hof, A. F. \& Roelfsema, M. The emission gap between the Copenhagen pledges and the 2 degree $\mathrm{C}$ climate goal: Options for Icosing and risks that could widen the gap. Global Environmental Change 21, 733-743 (2011).

12. UNEP. The Emission Gap Report 2010: Are the Copenhagen Pledges Sufficient to Limit Global Warming to 2 degrees Cor 1.5 degrees C? (2010).

13. Thompson, A. Management under anarchy: the international politics of climate change. Climatic Change 78, 7-29 (2006).

14. Aldy, J. E. The crucial role of policy surveillance in international climate policy. Climatic Change 126, 279-292 (2014).

15. Aldy, J. E. Designing a Bretton Woods Institution to Address Climate Change. (2012).

16. Manne, A., Mendelsohn, R. \& Richels, R. MERGE. Energy Policy 23, 17-34 (1995).

17. Aldy, J. E. Evaluating Mitigation Effort: Tools and Institutions for Assessing Nationally Determined Contributions. (2015).

18. Houser, T. Copenhagen, the accord, and the way forward. (Peterson Institute for International Economics Washington, DC, 2010).

19. Dellink, R., Briner, G. \& Clapp, C. Costs, revenues, and effectiveness of the Copenhagen Accord emission pledges for 2020. (2010).

20. McKibbin, W. J., Morris, A. C. \& Wilcoxen, P. J. Comparing climate commitments: a model-based analysis of the Copenhagen Accord. Climate Change Economics 2, 79-103 (2011).

21. Clarke, L. et al. International climate policy architectures: Overview of the EMF 22 International Scenarios. Energy Economics 31, Supplement 2, S64-S81 (2009).

22. Kriegler, E., Tavoni, M., Riahi, K. \& Van Vuuren, D. P. INTRODUCING THE LIMITS SPECIAL ISSUE. Climate Change Economics 4, 1302002 (2013). 
Accepted Nature Climate Change 2016, doi:10.1038/nclimate3106, available online at http://www.nature.com/nclimate/journal/vaop/ncurrent/full/nclimate3106.html.

23. Kriegler, E. et al. Making or breaking climate targets: The AMPERE study on staged accession scenarios for climate policy. Technological Forecasting and Social Change doi:10.1016/j.techfore.2013.09.021

24. Tavoni, M. et al. Post-2020 climate agreements in the major economies assessed in the light of global models. Nature Clim. Change 5, 119-126 (2015).

25. Fawcett, A. A. et al. Can Paris pledges avert severe climate change? Science 350, 1168-1169 (2015).

26. Cai, Y., Judd, K. L. \& Lontzek, T. S. The Social Cost of Carbon with Economic and Climate Risks. (2015).

27. Stern, D. I., Pezzey, J. C. V. \& Lambie, N. R. Where in the world is it cheapest to cut carbon emissions?*. Australian Journal of Agricultural and Resource Economics 56, 315-331 (2012).

28. Bodansky, D. M., Hoedl, S. A., Metcalf, G. E. \& Stavins, R. N. Facilitating linkage of climate policies through the Paris outcome. Climate Policy 1-17 (2015). doi:10.1080/14693062.2015.1069175

29. Cooper, Richard. The case for charges on greenhouse gas emissions. in Post-Kyoto International Climate Policy: Implementing Architectures for Agreement (eds. Stavins, R. N. \& Aldy, J. E.) 151-78 (Cambridge University Press, 2010). 
Accepted Nature Climate Change 2016, doi:10.1038/nclimate3106, available online at http://www.nature.com/nclimate/journal/vaop/ncurrent/full/nclimate3106.html.

Correspondence and requests for materials should be addressed to Joseph E. Aldy, joseph aldy@hks.harvard.edu.

Acknowledgments

The Research Institute of Innovative Technology for the Earth provided financial support for this project. LC, JE, GI, and HM were supported by the Global Technology Strategy Project. The views expressed here reflect those of the individual authors and not necessarily those of EPRI or its members.

\section{Author Contributions}

J.A., K.A., W.P., M.T. were responsible for project planning and scenario design. K.A., L.A.R., G.B., C.C., L.E.C., J.E., G.C.I., H.C.M., R.R., S.R., F.S., M.T. contributed to the modeling results. J.A., L.A.R., W.P., and M.T. undertook the synthesis of analyses. J.A., W.P., and M.T. drafted the paper. 
Accepted Nature Climate Change 2016, doi:10.1038/nclimate3106, available online at http://www.nature.com/nclimate/journal/vaop/ncurrent/full/nclimate3106.html.

\section{Figures and Tables}

Figure 1: Average 2025-2030 mitigation costs and emission reductions for the four models and seven major economies. Costs are scaled by GDP.

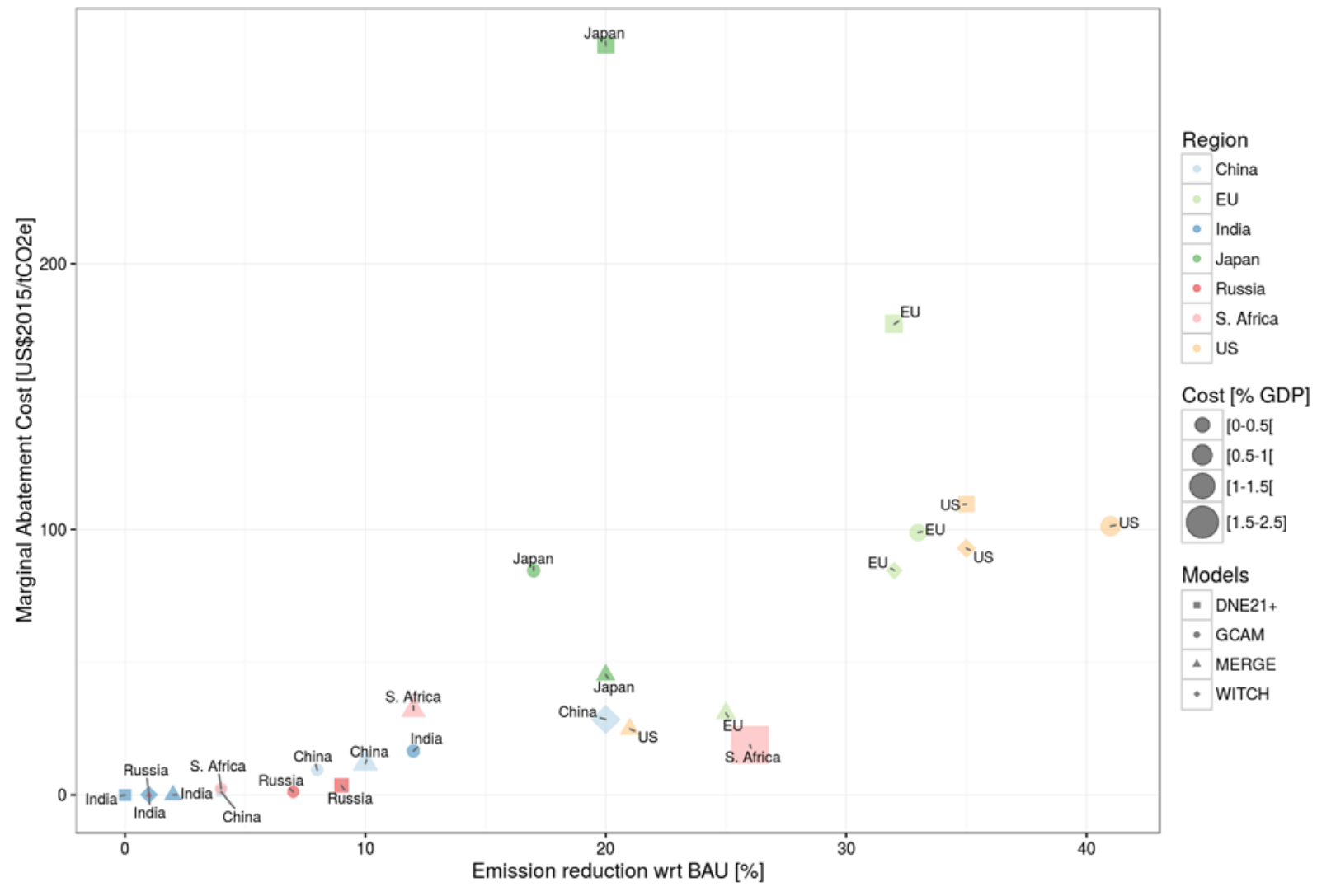


Accepted Nature Climate Change 2016, doi:10.1038/nclimate3106, available online at http://www.nature.com/nclimate/journal/vaop/ncurrent/full/nclimate3106.html.

Figure 2: Average 2025-2030 marginal abatement costs for the four models. The boxplots show the ranges of the USG Social Cost of Carbon and the marginal abatement costs in 2030 for scenarios consistent with $2^{\circ} \mathrm{C}$, as in the IPCC AR5 database. The orange stars represent the mean and the boxes show the 10th, 50th and 90th percentiles. See Methods for details on distributions of the SCC and costminimizing path to limit warming to $2^{\circ} \mathrm{C}$. The red, blue and green lines show the marginal costs predicted by three models assuming an international carbon market with free trade of $\mathrm{CO}_{2} \mathrm{e}$ permits or harmonized global carbon tax.

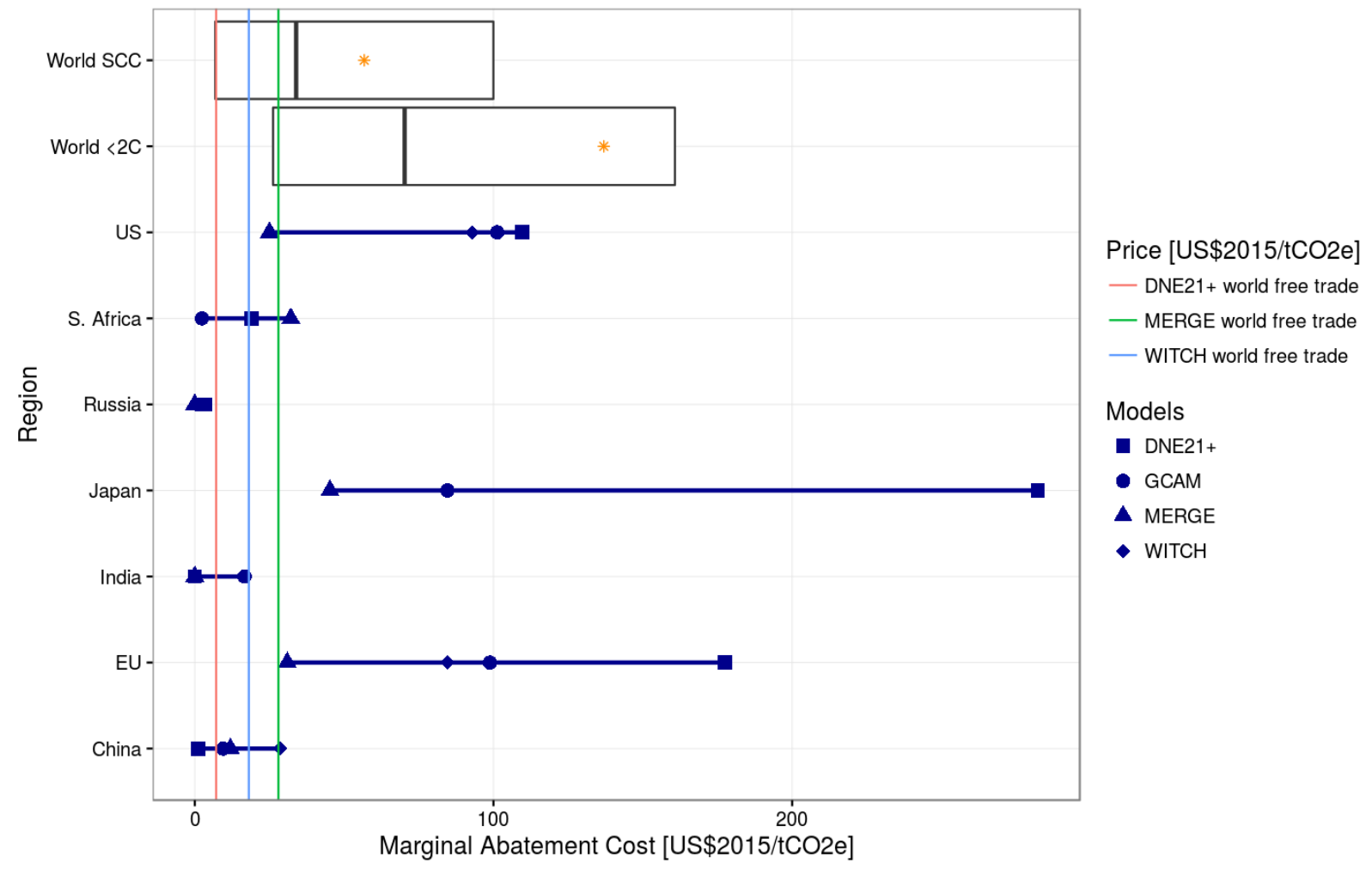


Accepted Nature Climate Change 2016, doi:10.1038/nclimate3106, available online at http://www.nature.com/nclimate/journal/vaop/ncurrent/full/nclimate3106.html.

Figure 3: Average 2025-2030 mitigation costs (marginal abatement costs on the vertical axis, and \% GDP losses proportional to markers size) in relation to average 2025-2030 per capita income for the four models, and seven major economies.

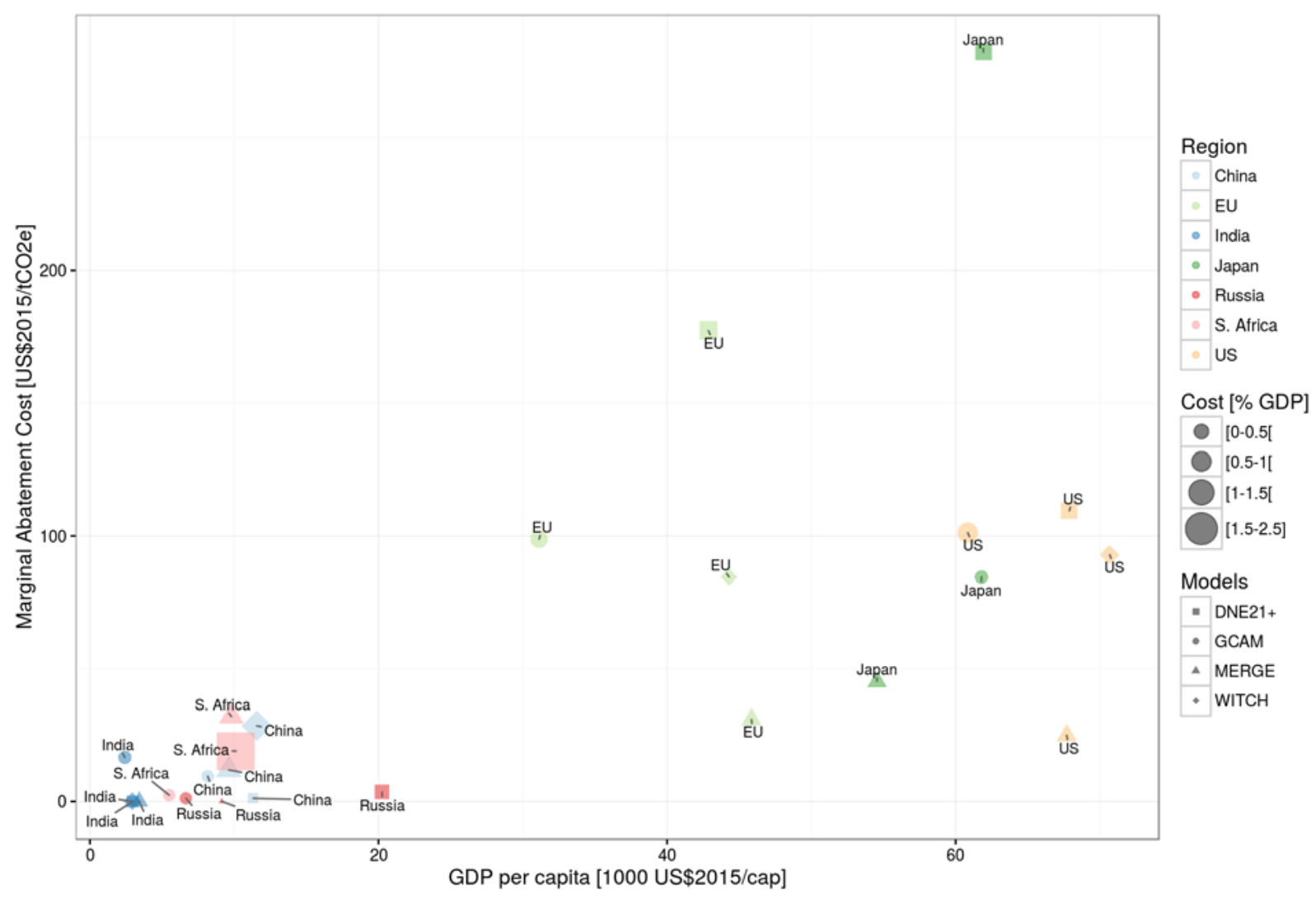


Accepted Nature Climate Change 2016, doi:10.1038/nclimate3106, available online at http://www.nature.com/nclimate/journal/vaop/ncurrent/full/nclimate3106.html.

Table 1. Ex ante assessment of the INDCs of select countries.

\begin{tabular}{|c|c|c|c|c|c|c|c|c|c|c|c|c|}
\hline & & \multicolumn{4}{|c|}{ Average Annual GHG Emissions 2025-2030 } & \multicolumn{2}{|c|}{ Annual GHG Change (\%) } & \multirow{2}{*}{$\begin{array}{l}\mathrm{CO}_{2} \text { Price } \\
\left(\$ / \mathrm{tCO}_{2} \mathrm{e}\right)\end{array}$} & \multicolumn{3}{|c|}{ Energy Price Change (\%) } & \multirow{2}{*}{$\begin{array}{c}\text { Cost } \\
(\% \text { GDP) }\end{array}$} \\
\hline & & Level & vs. 1990 & vs. 2005 & vs. BAU & $2015-25$ & $2015-30$ & & Electricity & Gasoline & Nat. Gas & \\
\hline \multirow{4}{*}{ ऽ| } & DNE21+ & 5,091 & -18 & -30 & -35 & -4.38 & -4.03 & 109 & 38 & 35 & 70 & 0.42 \\
\hline & WITCH & 5,140 & -5 & -26 & -35 & -5.50 & -4.29 & 101 & 38 & 53 & 72 & 0.76 \\
\hline & GCAM & 4,358 & -29 & -34 & -41 & -4.83 & -4.83 & 100 & 40 & 56 & 83 & 0.84 \\
\hline & MERGE & 5,407 & -7 & -22 & -21 & -2.70 & -3.68 & 40 & 48 & 22 & 28 & 0.28 \\
\hline \multirow{4}{*}{ 기 } & DNE21+ & 3,733 & -35 & -30 & -32 & -2.73 & -3.30 & 177 & 30 & 28 & 44 & 0.59 \\
\hline & WITCH & 3,720 & -32 & -30 & -32 & -4.43 & -4.39 & 116 & 12 & 39 & 91 & 0.51 \\
\hline & GCAM & 3,500 & -38 & -32 & -33 & -3.73 & -3.73 & 100 & 28 & 55 & 81 & 0.57 \\
\hline & MERGE & 3,836 & -30 & -25 & -25 & -1.98 & -3.01 & 45 & 29 & 29 & 31 & 0.31 \\
\hline \multirow{4}{*}{ | } & DNE21+ & 17,353 & 338 & 109 & -4 & -4.62 & -4.31 & 1 & -5 & -2 & 0 & -0.20 \\
\hline & WITCH & 16,526 & 413 & 91 & -20 & -4.39 & -4.02 & 33 & 46 & 15 & 25 & 1.60 \\
\hline & GCAM & 13,809 & 149 & 49 & -8 & -4.16 & -4.05 & 12 & 9 & 5 & 7 & 0.04 \\
\hline & MERGE & 13,086 & 250 & 77 & -10 & -3.83 & -3.65 & 23 & 31 & 14 & 16 & 0.72 \\
\hline \multirow{4}{*}{ 뭉 } & DNE21+ & 6,366 & 389 & 206 & 0 & -1.83 & -1.80 & 0 & -4 & -3 & 0 & 0.00 \\
\hline & WITCH & 4,577 & 278 & 115 & -1 & -2.72 & -2.61 & 0 & 0 & -2 & -1 & 0.59 \\
\hline & GCAM & 5,007 & 220 & 121 & -12 & -2.65 & -2.62 & 19 & 16 & 9 & 13 & 0.13 \\
\hline & MERGE & 4,787 & 308 & 135 & -2 & -2.42 & -2.52 & 0 & 2 & 6 & 7 & 0.12 \\
\hline \multirow{3}{*}{ 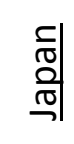 } & DNE21+ & 1,107 & -13 & -21 & -20 & -3.29 & -3.54 & 283 & 48 & 49 & 36 & 0.47 \\
\hline & GCAM & 1,139 & -12 & -21 & -17 & -2.27 & -2.24 & 91 & 40 & 46 & 69 & 0.13 \\
\hline & MERGE & 1,037 & -12 & -23 & -20 & -1.87 & -2.23 & 43 & 26 & 25 & 29 & 0.22 \\
\hline \multirow{3}{*}{ 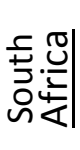 } & DNE21+ & 525 & 50 & 18 & -26 & -2.38 & -3.20 & 19 & 33 & 4 & 0 & 2.11 \\
\hline & GCAM & 503 & 10 & -12 & -4 & -1.00 & -0.98 & 2 & 2 & 1 & 1 & 0.01 \\
\hline & MERGE & 543 & 33 & 13 & -12 & -2.08 & -2.38 & 39 & 49 & 32 & 27 & 0.64 \\
\hline \multirow{3}{*}{ 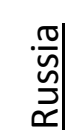 } & DNE21+ & 2,383 & -29 & 12 & -9 & -5.12 & -5.00 & 4 & 9 & 2 & 11 & 0.23 \\
\hline & GCAM & 2,481 & -26 & 7 & -7 & -2.09 & -2.23 & 2 & 3 & 0 & 0 & 0.01 \\
\hline & MERGE & 1,767 & -43 & -12 & -1 & -2.17 & -1.97 & 0 & 1 & 4 & 4 & -0.47 \\
\hline
\end{tabular}


Accepted Nature Climate Change 2016, doi:10.1038/nclimate3106, available online at http://www.nature.com/nclimate/journal/vaop/ncurrent/full/nclimate3106.html.

Notes: For the US, China, and Russia, we have employed the midpoint in their INDC range. Marginal cost is aggregated based on mitigated emissions. MERGE results are 2030. 
Accepted Nature Climate Change 2016, doi:10.1038/nclimate3106, available online at http://www.nature.com/nclimate/journal/vaop/ncurrent/full/nclimate3106.html.

\section{Methods}

In order to generate the set of metrics shown in the main analysis, we have employed four integrated assessment models: DNE21+, GCAM, MERGE, and WITCH.

\section{Description of the models used in this paper}

DNE21+

DNE21+ (Dynamic New Earth 21 Plus) is an energy and global warming mitigation assessment

model developed by RITE. ${ }^{30,31}$ The model is an intertemporal linear programming model for assessment of global energy systems and global warming mitigation in which the worldwide costs are to be minimized. The model represents regional differences, and assesses detailed energy-related $\mathrm{CO}_{2}$ emission reduction technologies up to 2050. When any emission restriction (e.g., an upper limit of emissions, emission reduction targets, targets of energy or emission intensity improvements, or carbon taxes) is applied, the model specifies the energy systems whose costs are minimized, meeting all the assumed requirements, including assumed production for industries such as iron \& steel, cement, and paper \& pulp, transportation by automobile, bus, and truck, and other energy demands. The energy supply sectors are hard-linked with the energy end-use sectors, including energy exporting/importing, and the lifetimes of facilities are taken into account so that assessments are made with complete consistency kept over the energy systems. Salient features of the model include (1) analysis of regional differences between 54 world regions while maintaining common assumptions and interrelationships, (2) a detailed evaluation of global warming response measures that involves modeling of about 300 specific technologies that help suppress global warming, and (3) explicit facility replacement considerations over the entire time period. The model assumes energy efficiency improvements of several kinds of technologies and cost reductions of renewable energies, carbon dioxide capture and storage (CCS) etc. for the future within the plausible ranges based on many literatures. 
Accepted Nature Climate Change 2016, doi:10.1038/nclimate3106, available online at http://www.nature.com/nclimate/journal/vaop/ncurrent/full/nclimate3106.html.

GCAM

GCAM is an open-source model primarily developed and maintained at the Pacific Northwest National Laboratory's Joint Global Change Research Institute. ${ }^{25,32}$ GCAM combines dynamic-recursive models of the global energy, economy, agriculture, and land-use systems with a reduced-form climate model, the Model for the Assessment of Greenhouse-Gas Induced Climate Change (MAGICC). Outcomes of GCAM are driven by assumptions about population growth, labor participation rates and labor productivity in 32 geo-political regions, along with representations of resources, technologies and policy. GCAM operates in 5-year time-steps from 2010 (calibration year) to 2100 by solving for the equilibrium prices and quantities of various energy, agricultural and GHG markets in each time period and in each region. GCAM tracks emissions of 16 GHG endogenously based on the resulting energy, agriculture, and land use systems. GCAM is a technology-rich model. It contains detailed representations of technology options in all of the economic components of the system. Individual technologies compete for market share based on their technology characteristics (efficiency in the production of products from inputs), and cost of inputs and price of outputs. The market share captured by a technology is based on an implicit probabilistic (logit) model of market competition. This formulation is designed to represent decision making among competing options when only some characteristics of the options can be observed.

\section{MERGE}

The MERGE model (Model for Evaluating Regional and Global Effects of greenhouse gas reduction policies) is an integrated assessment model describing global energy-economy-climate interactions with regional detail. It was introduced by Manne et al. ${ }^{16}$ and has been continually developed since; a recently published description is in Blanford et al. ${ }^{33}$ MERGE is formulated as a multi- 
Accepted Nature Climate Change 2016, doi:10.1038/nclimate3106, available online at http://www.nature.com/nclimate/journal/vaop/ncurrent/full/nclimate3106.html.

region dynamic general equilibrium model with an energy system of intermediate detail and a reducedform representation of the climate. It is solved as a sequential joint non-linear optimization with Negishi weights to balance inter-regional trade flows. The economy is represented as a top-down Ramsey model in which electric and non-electric energy inputs are traded off against capital and labor and production is allocated between consumption and investment. The energy system includes explicit technologies for electricity generation, refining, passenger vehicles, and other non-electric energy supply, with a resource extraction model for fossil fuels and uranium.

WITCH

WITCH (World Induced Technical Change Hybrid Model) is an energy-economy-climate model developed within FEEM's Sustainable Development research programme. ${ }^{34}$

The model divides the worldwide economy into 13 regions, whose main macroeconomic variables are represented through a top-down inter-temporal optimal growth structure. This approach is complemented with a bottom-up like description of the energy sector, which details the energy production, and provides the energy input for the economic module and the resulting emission input for the climate module. The endogenous representation of R\&D diffusion and innovation processes constitute a distinguishing feature of WITCH, allowing to describe how R\&D investments in energy efficiency and carbon free technologies integrate the currently available mitigation options.

The model can be used to evaluate the impacts of different climate policies on the optimal economic response over the century of the different regions. These can behave as forward-looking agents optimizing their welfare in a non-cooperative, simultaneous, open membership game with full information, or can be subject to a global social welfare planner in order to find a cooperative first-best optimal solution. In this game-theoretic set-up, regional strategic actions interrelate through GHG 
Accepted Nature Climate Change 2016, doi:10.1038/nclimate3106, available online at

http://www.nature.com/nclimate/journal/vaop/ncurrent/full/nclimate3106.html.

emissions, dependence on exhaustible natural resources, trade of oil and carbon permits, and

technological R\&D spillovers.

\section{Comparison of models main exogenous assumptions and baselines}

The models' assumptions have not been harmonized, in order to maintain the models' own set of assumptions for the main exogenous drivers, such as population and to some extent GDP.

The four models show similar patterns for business-as-usual emissions, population, and economic activity through 2030 . The geographical distribution is also very similar across models.

GHG emissions differ across models, since this in an output parameter which depends on a variety of factors, including energy prices and techno-economic specification for the energy technologies. Global emissions are nonetheless similar across models, and somewhat above $60 \mathrm{GtCO}_{2} \mathrm{e}$ by 2030, in line with the central projections of the IPCC WGIII (Chapter 6, Figure 6.5).

\section{Description of INDCs and their implementation in the models}

Let us describe how we have used our four modeling tools in light of the reasons for economic analysis in INDC assessment elaborated above. We reviewed each country's mitigation pledge in its INDC submission (http://www4.unfccc.int/submissions/INDC/) and all modeling runs assume simultaneous implementation of all INDCs. Implementation is assumed to minimize the costs necessary to achieve the emissions goal established in a respective country's INDC. Many of the INDCs require economic forecasts to translate into levels as countries like China and India submitted mitigation pledges in terms of a reduction in emission intensity. We used the models' GDP forecasts - coupled with the INDCs' specified reductions - to estimate the effective emission levels in the INDCs. Using an internally consistent set of economic and emission forecasts can circumvent the potential problem in both comparing mitigation effort and assessing aggregate effects that arise when countries use different 
Accepted Nature Climate Change 2016, doi:10.1038/nclimate3106, available online at http://www.nature.com/nclimate/journal/vaop/ncurrent/full/nclimate3106.html.

economic and energy price assumptions in their own forecasts. In each model we assume that countries implement their INDCs by minimizing total costs, which requires equating marginal abatement costs among all sources within a given country. Regarding the land use sector, the emissions reductions are implemented by applying the same tax as the energy system for the models representing land use.

To enable an apples-to-apples comparison and avoid potential bias owing to variation in target years, we have focused on the 2025-2030 average in our modeling results with the exception of results from the MERGE, which only reports output in 10-year time steps. For multi-country regions in the models, we converted national pledges to emission limits and aggregated these to the regional level. The following describes model-specific elements to the evaluation of the INDCs.

DNE21+

Similarly, the implementation of the INDCs was carried out via emission caps on total country and (where countries are aggregated) regional level of GHG. The forecasts were developed by RITE. Economic forecasts are consistent with the reference forecasts published by IEA and EIA. Business-asusual emission forecasts are comparable to other energy-economy and IAM forecasts, except DNE21+ excludes explicit, existing climate policies. In contrast to EIA and EIA emission forecasts, the DNE21+ approach gives credit to countries for those existing carbon pricing policies when measuring emission changes and costs against BAU forecasts. Each country or region implements its INDC with an economywide carbon price necessary to meet the emission caps.

GCAM

Countries achieve their INDCs by means of a uniform price on carbon across sectors. All 2025 and 2030 INDC goals are assumed to be met. The reference, business-as-usual scenario, does not include new climate policies implemented after 2010. The approach is consistent with many reference 
Accepted Nature Climate Change 2016, doi:10.1038/nclimate3106, available online at http://www.nature.com/nclimate/journal/vaop/ncurrent/full/nclimate3106.html.

scenarios in the literature, including the IPCC AR5 scenarios. The INDC scenarios include, where appropriate, the countries' 2020 Copenhagen goals as well as their 2025/2030 INDC goals. The supplemental information for Fawcett et al. ${ }^{25}$ provides extensive detail on the reference and INDC scenarios.

MERGE

The following countries and regions have $\mathrm{CO}_{2}$-equivalent emission targets for 2030 based on their INDCs: the United States, the European Union, China, India, Japan, Russia, South Korea, and South Africa. For the United States, its 2025 target is extrapolated to 2030 to conform to the 10 -year timestep of the model. China's target is specified in terms of $\mathrm{CO}_{2}$-only emission intensity of GDP and peaking in 2030 in carbon dioxide emissions. Where appropriate, 2020 targets based on the Copenhagen goals are assumed for these countries. An economy-wide carbon price is employed within each country (or, in the case of the EU, region) to deliver on the INDC emission goal.

WITCH

The implementation of the INDCs was carried out via emissions caps on the total regional level of GHG, with the exception of China where the limit was established only for $\mathrm{CO}_{2}$ as in the INDC. The reference case used was the SSP2 with business as usual (BAU) future projection, except when the BAU level was explicit in the INDC. The EU28 regional is divided in two regions for which the same relative emission target has been set and they are allowed to freely trade emission permits. The reported emissions include emissions from land use which are deduced from the market biomass price, in this setting these emissions are taxed at the same rate as the energy sector. The historical emissions used for reporting were the WDI and the FAO (for land use) databases. Each country or region implements its INDC with an economy-wide carbon price necessary to meet the emission caps. 


\section{Metrics}

Regarding the set of the metrics used, we define GHG emissions as the sum of the six Kyoto gases, thus excluding aerosols. DNE21+ assumes the INDC target is achieved by emission reductions excluding land use emissions, which are not modeled. The GDP used in the intensity calculations is based on market exchange rates (MER). Prices in the models are expressed in 2005 USD, and measured at the secondary level for energy, which we have converted to 2015 USD using the GDP implicit price deflator. Economic costs are expressed as a share of GDP.

\section{Social Cost of Carbon Distribution}

We have extracted the 150,000 SCC estimates for the year 2030 based on a 3\% discount rate from the most recent USG update of the social cost of carbon. ${ }^{35}$ The USG SCC estimates reflect the consideration of various degrees of parameter uncertainty in the three deterministic integrated assessment models used in the USG exercise. We have presented the mean SCC and the $10^{\text {th }}$ and $90^{\text {th }}$ percentiles of the SCC distribution for 2030, converted from 2007 USD to 2015 USD using the GDP implicit price deflator (CEA 2016). While this represents one way of illustrating uncertainty in the SCC, it is important to recognize alternative approaches to incorporating uncertainty in the modeling framework - such as in dynamic stochastic general equilibrium models ${ }^{26}$ - that may better represent how uncertainty influences the social cost of carbon.

\section{Distribution of Cost-Minimizing Path to Limiting Warming to $2^{\circ} \mathrm{C}$}

We have extracted 186 marginal abatement cost estimates from the IPCC AR5 scenario database (https://secure.iiasa.ac.at/web-apps/ene/AR5DB/) for all model runs that would limit warming to no more than $2^{\circ} \mathrm{C}$ with at least a $50 \%$ probability. We have presented the mean value and the $10^{\text {th }}$ and $90^{\text {th }}$ 
Accepted Nature Climate Change 2016, doi:10.1038/nclimate3106, available online at http://www.nature.com/nclimate/journal/vaop/ncurrent/full/nclimate3106.html.

percentiles of this distribution for 2030, converted from 2005 USD to 2015 USD using the GDP implicit price deflator. ${ }^{36}$

\section{Caveats in Comparing Modeling Estimates to SCC and Cost-Minimizing Path to Limiting Warming to $2^{\circ} \mathrm{C}$}

We have compared the modeling estimates of the INDCs using our four modeling platforms with the USG SCC estimates and the IPCC AR5 scenario database for model runs that would limit warming to no more than $2^{\circ} \mathrm{C}$ with at least a $50 \%$ probability. These comparisons are intended to be illustrative, but it is important to recognize several caveats. First, the underlying reference assumptions in our models differ from the underlying assumptions used in the SCC analyses and the AR5 modeling scenarios. The consideration of uncertainty also differs among these sets of analyses. Second, the SCCs represent the benefit of the first unit of emissions abatement while the marginal costs represent the costs of the last unit of abatement. These differences may be small for modest levels of emission abatement but large for globally significant levels of emission abatement. Finally, our modeling analyses and those in the AR5 modeling scenarios assume idealized, economy-wide carbon pricing policies. Thus, the reported marginal and total costs of abatement in our modeling analyses and the AR5 scenarios may be lower than those associated with actual policy implementation. 
Accepted Nature Climate Change 2016, doi:10.1038/nclimate3106, available online at http://www.nature.com/nclimate/journal/vaop/ncurrent/full/nclimate3106.html.

Methods References

30. Akimoto, K. et al. Comparison of marginal abatement cost curves for 2020 and 2030: longer perspectives for effective global GHG emission reductions. Sustainability Science 7, 157-168 (2012).

31. Akimoto, K. et al. Estimates of GHG emission reduction potential by country, sector, and cost. Energy Policy 38, 3384-3393 (2010).

32. Joint Global Change Research Institute. Global Change Assessment Model v. 4.2 (Pacific Northwest National Laboratory, 2015); http://www.globalchange.umd.edu/archived-models/gcam/download/.

33. Blanford, G., Merrick, J., Richels, R. \& Rose, S. Trade-offs between mitigation costs and temperature change. Climatic Change 123, 527-541 (2014).

34. Bosetti, V., Carraro, C., Galeotti, M., Massetti, E. \& Tavoni, M. WITCH: A world induced technical change hybrid model. The Energy Journal 27, 13-38 (2006).

35. United States Government. Technical Support Document: Technical Update of the Social Cost of Carbon for Regulatory Analysis Under Executive Order 12866. (2015).

36. Council of Economic Advisers. Economic Report of the President. (2016). 